\title{
PEDAGOGICAL CONDITIONS OF TOLERANT ATTITUDE OF SCHOOL AND FAMILY TO CHILDREN OF PRIMARY SCHOOL AGE
}

\author{
Hanna Lulka ${ }^{1}$ \\ Marina Grinova ${ }^{2}$
}

DOI: https://doi.org/10.30525/978-9934-26-001-8-1-7

\begin{abstract}
The phenomenological analysis of the essence of the concept of «tolerance» is carried out in the work; different possibilities of considering certain types of tolerance, the criteria of tolerance are characterized, the term «tolerant attitude» is analyzed, the content of the family's tolerant attitude to young school children is revealed.

We have identified several levels of pedagogical conditions. The structure of the teacher's tolerant attitude to students is characterized, which is presented in the interaction of three leading components: The concept of «interaction» is defined, which is defined as a universal form of development that changes interacting objects that appear and lead each of them in a new way. Typical teacher interactions with young students, such as dialogue, cooperation and description, are highlighted. It was found that the main components of tolerance of young school-age children include: knowledge of tolerance, knowledge of the existence of differences in culture and ways of thinking about another ethnic, national or cultural background; formation of a friendly attitude to another person, as well as interest in gaining some experience of communication with representatives of another culture; development of cultural communication skills and conflict resolution skills. Thus, the results of theoretical and methodological analysis of scientific literature with research problems allowed to structure its categorical apparatus and organize an experimental study of pedagogical conditions of tolerant attitude to school and family to primary school students.
\end{abstract}

\footnotetext{
${ }^{1}$ Postgraduate Student of the Department of General Pedagogy and Andragogy, Poltava National Pedagogical University named after V.G. Korolenko, Ukraine ${ }^{2}$ Doctor of Pedagogical Sciences, Corresponding Member of the NAPS of Ukraine, Professor at the Department of Pedagogical Skills and Management, Poltava National Pedagogical University named after V.G. Korolenko, Ukraine
} 
In the section «Experimental study of pedagogical conditions of formation of tolerant attitude of school and family to children of young school age» the initial state of levels of tolerant attitude to pupils of initial classes is revealed; substantiated correctional program for the formation of a tolerant attitude of parents and teachers to young students in the process of pedagogical communication; the procedure and results of monitoring were carried out, which confirms the effectiveness of the experimental study.

The study was conducted in accordance with the prices and objectives created in the work. By identifying the levels (high, medium, lower than average, low) of tolerant attitude to young students in the process of pedagogical communication, certain criteria were identified: meaningful, emotional, sensory, communicative and relevant indicators were developed.

The quality of research methods were: description of teachers, testing, ascertaining experiment, mathematical and statistical methods of processing research materials. Parental intolerance is a factor in the object development of the child's personality (socio-pedagogical neglect), which manifests itself in the unformed in the authorities of the subject of self-awareness, communication and activity and concentrated development in the disturbed image of «I», socio-psychological maladaptation. Thus, solving the problems of parental tolerance requires parenthood, due to the violation of family upbringing, due to the intolerant attitude of parents to others, one of them and the children. The obtained information complements the scientific ideas about the psychology of parenthood in parts regarding the formation of the structure of parental tolerance and its interaction with the development of the child's personality.

\section{Introduction}

A professionally competent primary school teacher is perceived in a society as a person who can establish contacts with all participants of the learning process (students, parents, colleagues), regardless of age, nationality, social status, belonging to different cultures, etc., thus asserting his or her own tolerant position. Therefore, the would-be teacher must be a bearer of humanistic values, able to show tolerant behavior and educate it in the youngest students [1, p. 53-55].

The study of legal documents, psychological and educational literature and teaching practical experience of training would-be primary 
school teachers in connection with research issues revealed a number of contradictions, namely:

- between urgent need of the society in educating a tolerant democratic personality and insufficient level of training primary school teachers;

- between theoretical development of the field of tolerant education, experience of its implementation and episodic reflection of the achievements in the educational process of teacher training;

- between modern requirements of the national educational system connected with implementation of the concept of a new Ukrainian school [2].

Relevance of the theme of the research runs from the fact that modern primary school has great potential for the formation of tolerant behavior in primary school children, the implementation of which through leisure in primary school can lead to a real change in child behavior, development and fixing tolerant behavior skills.

In today's world, the task of forming tolerant behavior of primary school children 1 should take place in all educational institutions, especially in those which have the opportunity to directly influence the formation of a personality of primary school children $[1, \mathrm{p}$. 54]. Such a social institution is an extensive school, ready to implement in its work the problem of formation in schoolchildren tolerant behavioral skills and develop humanistic values of each student. The choice of the theme of the research «Pedagogical conditions of tolerant attitude of school and family to children of primary school age» is dictated by the urgency of the problem, the lack of its theoretical development and actual research in the field as well as the urgent need to overcome these contradictions.

The results of the study can be used during the work on school curriculums and professional programs; techniques of conducting classesand planning teaching practices in the conditions of general educational institutions; in the system of pedagogical education in the refresher teachers' courses for primary school teachers; in the process of development of textbooks and guidelines on the problem under discussion.

\section{Diagnosis of tolerant attitude of school and family to children of primary school age}

To teach primary school children respectful and tolerant communication with each other is a multifaceted process in the educational activities of 
primary school teachers. Before starting our own research, recent periodicals and internet resources of last decade, concerning the achievements and experience of educators in dealing with the problem, have been studied. Analyses of teachers' experience show that most of them are aware and concern about the problem of educating junior students tolerant attitudes, but the number of issues on the problem is very small $[5 ; 6 ; 8 ; 9 ; 11]$.

The participants of the experiment were teachers of secondary schools, namely: Municipal Institution known № 2 (Poltava Secondary School I-III degrees), Poltava Municipal Scientific Lyceum № 3, Taras Shevchenko Poltava Secondary School № 7, Poltava Gymnasium № 17, Poltava Secondary School № 37. There were all in all 337 respondents (51 primary school teachers and 286 respondents are parents of the schoolchildren).

The approach to choosing respondents allowed to identify the general patterns of pedagogical tolerance, regardless of the academic school discipline.

The research is being conducted according to the goals and objectives set up in the work. The research technique includes questioning, testing, stating experiment and mathematic statistic ways of obtaining scientific data.

The experiment was conducted under the usual conditions of pedagogical activity of teachers and parents, was aimed at studying the personal level of pedagogical tolerance, the psychological content of pedagogical tolerance [13]. The following techniques of collecting empirical data were used to study pedagogical tolerance: - determination of communicative tolerance suggested by V.V. Boyko.

To study typical individual features of tolerance and intolerance of teachers, the method of multifactorial study of 16PF Cattell's personality was used. Mathematical processing of empirical data was carried out by mathematical and statistical methods in the program STATISTICA 6.0, SPSS.

Parental intolerance is a factor in the objective development of a child's personality (socially and educationally neglected in most cases) which manifests itself in the absence of apersonality traits of self-actualization, communication and activity that is expressed in dysfunction of personal image, social and psychological disadaptation.

Thus, solution of the problem of parental tolerance is necessary for parents as non-observance in family education is caused by parents' intolerant attitude to others, to each other and to the child. The information obtained complements the scientific understanding of the psychology of 
parenthood in terms of substantiating the structure of parental tolerance and its relationship with the development of the child's personality.

In the process of studying the levels of tolerance of parents of primary school children, a number of assumptions were made.

On the basis of the correlation analysis empirical confirmation of theoretical model of structure of parental tolerance, allocation in it of peculiarities of the subjective / object development of the child's personality [4, p. 45-57].

The correlation study used the following methods: the questionnaire «Conscious parenting», the method of diagnosis of parental relationship (DBV) by A.Ya. Varga - V.V. Stolin, the method of diagnosis of general communicative tolerance by V.V. Boyko.

The study involved 103 complete families (286 respondents) who are married and have a common child of primary school age (from 6 to 9 years). The sample included families with different social and financial status, age and level of education.

\section{Analysis of the results of the experimental study of the formation of a tolerant attitude of school and family to children of primary school age}

Pedagogical tolerance, in our opinion, is one of the professionally important qualities of a teacher's personality, which is a social category and is manifested in the attitude of accepting another person, empathic understanding, open and trusting communication.

The content of the personality profile of a teacher with a high and low level of communicative and pedagogical tolerance according to Kettell. Analyzing the profileof an individual, tolerance / intolerance of teachers according to the picture it's possible to state that principal differences of profiles are observed in the scales: low intellect high intellect, emotional instability - emotional stability, trustfulness - distrust, simplicity - deceit, convicted adequacy - disposition to survival guilt, low strain - high strain, low anxiety - high anxiety.

Profile analysis allows us to note not only the most pronounced personality traits of a tolerant - intolerant teacher, but also to assess the personality as a whole. The personality profile of a teacher with a high level of tolerance includes high scores on scales $\mathrm{B}, \mathrm{C}, \mathrm{H}$, extraversion 
and minimal scores on scales L, Q2, Q4 and anxiety. Assessment by factor $\mathrm{B}=7$, which involves high mental abilities, insight, high level of education, broad intellectual interests [3, p. 297-300]. There is an emotional stability factor $\mathrm{C}=8$ and a low level of anxiety. The extroverted personality of this factor is equal to 7 , which is confirmed by the factor $\mathrm{H}=7$, these factors in combination indicate the activity of teachers in contact with people, they do not experience difficulties in communication, show friendliness and sensitivity. In conflict situations they are not susceptible to threats.

The minimum indicator for the factor $\mathrm{L}$ indicates that teachers with a high level of pedagogical tolerance are flexible to change, do not expect hostility to their address, easily reconcile, do not seek to compete, are more inclined to dialogue and cooperation. A rather low Q2 factor indicates that the teacher may be dissatisfied with the separate work. The personality profile of the teacher's intolerance includes

high scores on the $\mathrm{N}, \mathrm{O}$ scales. A person with a fairly high score on the $\mathrm{N}$ factor is able to keep others at a sufficient distance in order to live more calmly. The ability to communicate with people is reduced by factor E. Inadequacy in communication with other people is exacerbated by high score by factor O. Teachers with a low level of pedagogical tolerance are characterized by suspicion, in relationships with people on whom something depends, sensitive to their approval or disapproval.

On analyzing the personality profile of a teacher of communicative pedagogical tolerance and communicative-pedagogical intolerance it is possible to determine the maximum differences on individual factors. The largest differences in such factors are presented in table 1.1, insignificant differences are not included in this table 1.1.

On analyzing the personality profile of tolerance and intolerance of teachers, we may assume that there will be significant differences between the structures of personality qualities of tolerance and intolerance of teachers. In table 1.2. the characteristics of the correlation matrix of indicators according to Kettell tolerance and intolerance of teachers are presented. It can be noted that the rate of divergence in teachers with a high level of communicative and pedagogical tolerance is higher than in teacher intolerance. This indicator affects the overall organization of the structure, which is much higher in tolerant teachers. 
Table 1.1

Portrait of a tolerant - intolerant teacher

\begin{tabular}{|c|c|c|c|c|c|}
\hline \multirow{2}{*}{$\begin{array}{l}\text { Tolerant } \\
\text { Teacher }\end{array}$} & \multicolumn{2}{|c|}{ Wall } & \multirow{2}{*}{$\begin{array}{c}\text { Intolerant } \\
\text { Teacher }\end{array}$} & \multicolumn{2}{|c|}{ Wall } \\
\hline & $\begin{array}{c}\text { Average } \\
\text { score }\end{array}$ & $\begin{array}{c}\text { Coefficient } \\
\text { of variation }\end{array}$ & & $\begin{array}{c}\text { Average } \\
\text { score }\end{array}$ & $\begin{array}{c}\text { Coefficient } \\
\text { of variation }\end{array}$ \\
\hline $\begin{array}{l}\text { High } \\
\text { intelligence }\end{array}$ & 6,9 & $\pm 0,14$ & $\begin{array}{l}\text { Low } \\
\text { intelligence }\end{array}$ & 5,8 & $\pm 0,13$ \\
\hline $\begin{array}{l}\text { Emotionally } \\
\text { stable }\end{array}$ & 7,8 & $\pm 0,13$ & $\begin{array}{l}\text { Emotionally } \\
\text { unstable }\end{array}$ & 5,9 & $\pm 0,13$ \\
\hline Credulity & 3,7 & $\pm 0,17$ & Suspicion & 5,2 & $\pm 0,15$ \\
\hline Insight & 5,6 & $\pm 0,14$ & Naivety & 6,7 & $\pm 0,16$ \\
\hline $\begin{array}{l}\text { Confident } \\
\text { adequacy }\end{array}$ & 5,7 & $\pm 0,13$ & $\begin{array}{l}\text { Propensity } \\
\text { to feel guilty }\end{array}$ & 7 & $\pm 0,12$ \\
\hline Low tension & 4,2 & $\pm 0,15$ & High tension & 5,7 & $\pm 0,13$ \\
\hline Low anxiety & 4 & $\pm 0,12$ & High anxiety & 6 & $\pm 0,14$ \\
\hline
\end{tabular}

Table 1.2

Characteristics of the correlation matrix of Kettell indicators of tolerant and intolerant teachers

\begin{tabular}{|l|c|c|}
\hline $\begin{array}{c}\text { Characteristics } \\
\text { of the correlation matrix }\end{array}$ & Tolerant teachers & Intolerant teachers \\
\hline Coherence & 44 & 32 \\
\hline Divergence & 7 & 19 \\
\hline General organization of the structure & 51 & 51 \\
\hline $\begin{array}{l}\text { The coefficient of the general } \\
\text { organization of the structure is }\end{array}$ & 0,17 & 0,11 \\
\hline
\end{tabular}

We can assume that the personality structure of tolerance and intolerance of teachers differs not only in general organization, but also qualitatively. Let's analyze the scheme of interrelation of personality qualities of tolerance and intolerance of teachers. The factors-cordiality, emotional stability, security, social courage - reinforce each other and help reduce frustration, irritability. Factors security and social courage weaken the influence of factor $\mathrm{O}$, that is, in conflict situations, when the teacher is wrong, guilt will not be a deterrent in solving the problem situations [12].

The personality structure of the teacher's intolerance is separated, formed by several groups of factors. Thus, high intelligence, emotional 
stability, trust, naivety, confident adequacy, the ability to contain anxiety, low tension and low anxiety are interrelated with pedagogical tolerance.

The main differences in the personality profiles of a tolerant-intolerant teacher are observed on the following scales: low intelligence - high intelligence, emotional instability - emotional stability, trust - suspicion, naivety - insight, confident adequacy - a tendency to guilt, low voltage high voltage, low anxiety - high anxiety [12]. As to the first stage of the study, one can come to the following generalizations.

It was found that the effectiveness of educational and training activities of teachers affect communicative and sociocultural tolerance. It is shown that a high level of teacher tolerance is provided, according to Kettell, by various combinations of personality traits. It is found that tolerant-intolerant teachers have different cognitive components, in particular tolerant teachers use differentiated assessments of the student's personality.

It is proved that pedagogical tolerance has a dynamic and reaches a peak during their 4-7 and 20-40 years of professional experience. In general, the results of the observational experiment reflect the general trend in the level of teachers' tolerant attitude towards younger students.

According to the cognitive criterion, $10.61 \%$ are high-level teachers, $54.54 \%$ are middle-level teachers and $34.85 \%$ are low-level teachers. Motivational component $12.12 \%$ - with high, 53.03\% - with medium, $34.85 \%$ - with low; behavioral $-10.6 \%, 59.09 \%$ and $30.3 \%$, respectively. The accuracy of matches and differences at the beginning and end of the experiment were determined by accounting the t-test. Accordingly, two hypotheses were formulated. Hypothesis H0: differences in the level of tolerant attitude of children of primary school age at the beginning and the end of the experiment are not significant enough. Hypothesis H1: differences in the level of tolerant attitude of teachers to children at the beginning and end of the experiment are quite significant.

To calculate the t-test, the variance was determined. The calculation of the variance of the formation of a tolerant attitude of teachers to children of primary school age is given in table 1.3 .

The variance was obtained, the value of the t-test was calculated: 
At the beginning of the experiment (\%)

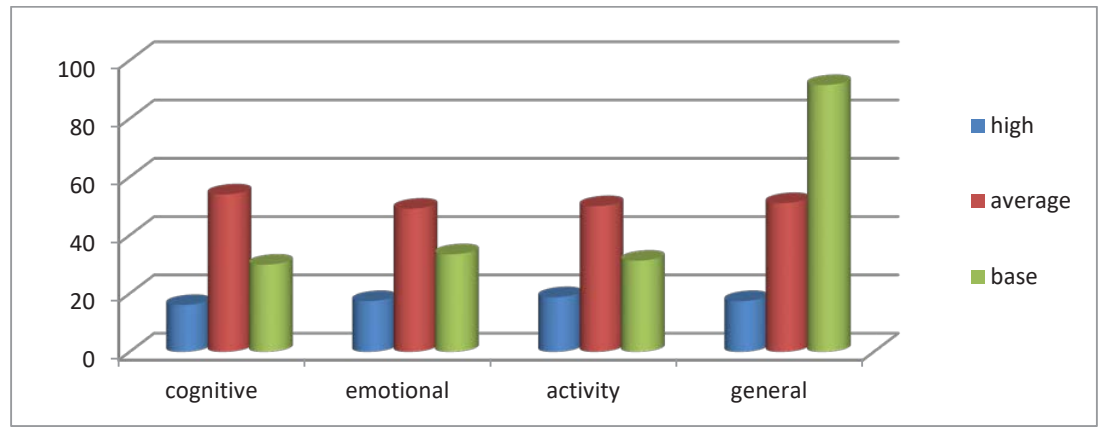

At the end of the experiment (\%)

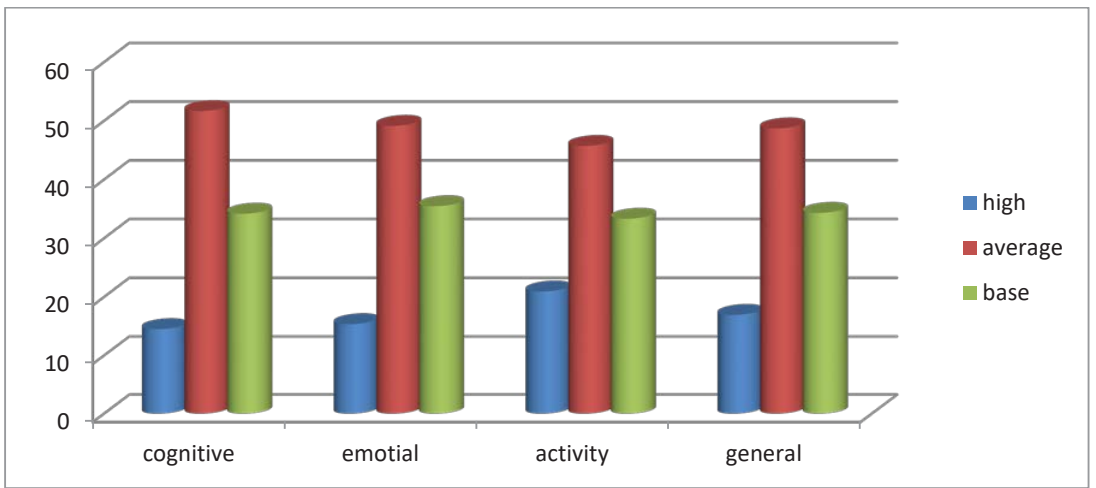

Figure 1.1. The level of formation of teachers' tolerant attitude towards children of primary school age according to the results of the observational experiment

Value of the table for t-test is less than that of estimated one (ttabl. $(1,96)>$ ntrazrach. $(1,52)$. That means that $\mathrm{H} 1$ hypothesis is rejected while HO hypothesis is accepted, which indicates homogeneity of the level of education of teachers to tolerant education of children of primary school age at the beginning and at the end of the experiment with $95 \%$ probability. The structure of communicative and pedagogical 
Table 1.3

Calculation of the variance of the formation of tolerant education of teachers to children of primary school age

\begin{tabular}{|c|c|c|c|c|c|c|c|}
\hline Groups & $\begin{array}{l}\text { Evalu- } \\
\text { ation }\end{array}$ & $\begin{array}{c}\text { Number } \\
\text { of } \\
\text { marks }\end{array}$ & $\begin{array}{c}\text { Average } \\
\text { score }\end{array}$ & $\begin{array}{l}\text { Devia- } \\
\text { tion }\end{array}$ & $\begin{array}{c}\text { Deviation } \\
\text { square }\end{array}$ & & $\mathbf{S}$ \\
\hline \multirow{3}{*}{$\begin{array}{l}\text { the } \\
\text { beginning } \\
\text { of the } \\
\text { experiment }\end{array}$} & 3 & 80 & \multirow{3}{*}{3,829} & $-0,829$ & 0,687241 & 2,061723 & \multirow{3}{*}{0,0388} \\
\hline & 4 & 114 & & 0,171 & 0,029241 & 0,116964 & \\
\hline & 5 & 40 & & 1,171 & 1,371241 & 6,856205 & \\
\hline \multirow{3}{*}{$\begin{array}{l}\text { end of } \\
\text { experiment }\end{array}$} & 3 & 71 & \multirow{3}{*}{3,857} & $-0,857$ & 0,734449 & 2,203347 & \multirow{3}{*}{0,0395} \\
\hline & 4 & 114 & & 0,143 & 0,020449 & \begin{tabular}{|l|}
0,081796 \\
\end{tabular} & \\
\hline & 5 & 39 & & 1,143 & 1,306449 & 6,532245 & \\
\hline
\end{tabular}

tolerance is specific to teachers with different work experience. In the course of empirical research the individual psychological qualities of the teacher's personality were refined. It is proved empirically that tolerance is professionally important trait for a teacher. Cognitive and individual psychological characteristics of communicative pedagogical tolerance is given. The hypothesis is confirmed. that high level of communicative pedagogical tolerance is achieved by different combinations of individual psychological traits of a teacher's personality. And also the hypothesis is confirmed that at different stages of professional activity communicative and pedagogical tolerance has different structure. Correlation analysis empirically confirmed the theoretical model of structure of parental tolerance. Reliability of the theoretical model was confirmedby high level of correlations between the individual components of parental tolerance (cognitive, emotional, behavioral) and between the individual elements within these components. Out of 6400 possible relationships $97(1.5 \%)$ is reliable connections where $\mathrm{n}=317, \mathrm{p} \leq 0.001$ has an emotional component, $39(0.6 \%)$ - cognitive, $15(0.2 \%)$ - behavioral component. These data confirm the idea of the existence of a system-forming factor of parental tolerance as an integral unity, which is an emotional component (Figure 1.2).

The main element of the emotional component in the number of intercorrelatingattitudes (70 reliable attitudes) are positive parental feelings to themselves as fathers, feelings of fatherhood, feelings to the child. 


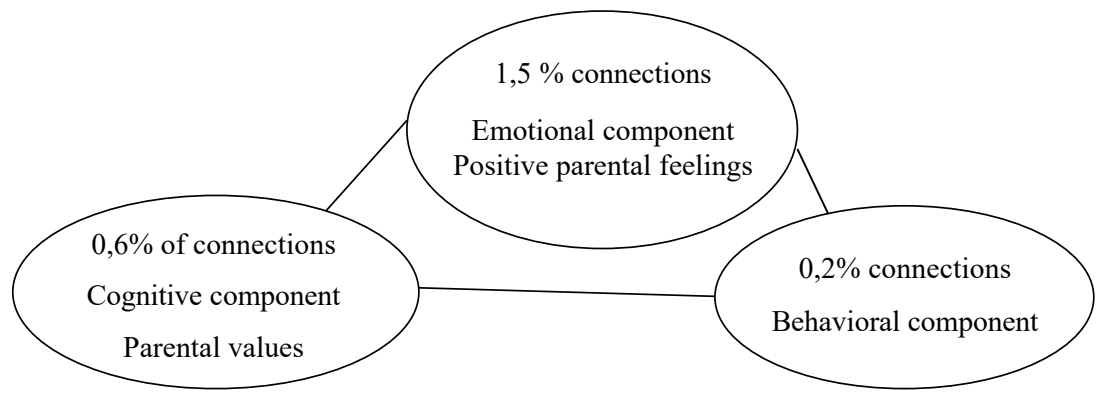

\section{Figure 1.2. Structure of parental tolerance as an integral part in formation father's personality}

The most important element of the cognitive component of parental tolerance was such an indicator of conscious parenting as parental (family) values ( 9 reliable connections). Within the behavioral component, the main element is parental attitude and style of family upbringing (11 reliable connections), which correlates with the awareness of parenthood in terms of parental attitudes, positions, attitudes towards the child, family upbringing style and parental responsibility. Communicative tolerance of parents has a direct connection with awareness of parenthood, positive parental feelings and relationships, including parental love and sympathy.

Thus, in general, in the structure of parental tolerance family values, positive parental feelings, parental attitudes and style of family upbringing are dominating. Parental tolerance is formed on the basis of the unconditional value of the child, positive parental feelings and is expressed in the humane attitude to the child and the democratic style of family upbringing. Tolerant parents have a high level of parenting awareness. They are satisfied with their parental role, consider themselves happy parents. They radiate positive feelings and strive to be the only whole with the child, take interest in the affairs of their child. Family upbringing adhere to a democratic style.

The second hypothesis was proved in the same way by a sample of parents of primary school children with low rates of parental awareness and communicative tolerance. In the structure of parental intolerance there are two system-forming features: the inability to hide their feelings ( 8 connections) and the desire to «fit» the child to oneself, to make it more «comfortable» 
(8 connections). Both features are part of the structure of communicative tolerance. Thus, parental intolerance is caused by general communicative intolerance. The third assumption is confirmed by a large number of reliable relationships (at $\mathrm{n}=5$, rcrit $=0.878$ for $\mathrm{p} \leq 0.05$ ) between the parameters of the child's personality development and parental tolerance (table 1.4).

A direct correlation between the parameters «subject of self-awareness» and cooperation as a type of parental attitude $(r=0.879)$ was found. Because neglected children have low rates of cooperation with their parents (mostly

Table 1.4

\section{Interconnection of parameters of parental tolerance with personality development}

\begin{tabular}{|c|c|c|}
\hline \multicolumn{2}{|c|}{ Correlative links between the parameters } & \multirow[b]{2}{*}{$\begin{array}{l}\text { Correlation coefficient } \\
\text { (r) at } \mathrm{n}=5 \text {, } \\
\text { rcrit }=0.878 \text { for } \mathrm{p} \leq 0.05\end{array}$} \\
\hline Cooperation & $\begin{array}{l}\text { Parameters of the child's } \\
\text { personality development } \\
0.879\end{array}$ & \\
\hline The symbiosis & $\begin{array}{l}\text { of the SS is the subject } \\
\text { of self-knowledge }\end{array}$ & 0,879 \\
\hline $\begin{array}{l}\text { Scale 3. Categoricalness or } \\
\text { conservatism in the assessments } \\
\text { of other people }\end{array}$ & ST - total anxiety level & 0,889 \\
\hline $\begin{array}{l}\text { Scale } 4 \text {. Inability to hide } \\
\text { or smooth out unpleasant } \\
\text { feelings when confronted with } \\
\text { uncommunicative qualities of } \\
\text { partners } \\
\text { LED is a subject of gaming } \\
\text { activity }\end{array}$ & & $-0,953$ \\
\hline $\mathrm{BP}$ - parental feelings & $\begin{array}{l}\text { SID - the subject of } \\
\text { gaming }\end{array}$ & $-0,980$ \\
\hline BV - parental responsibility & ST - total anxiety level & 0,889 \\
\hline $\begin{array}{l}\text { Scale 3. Positive feelings } \\
\text { towards the child are due to his } \\
\text { strengths and achievements }\end{array}$ & $\begin{array}{l}\text { ST - general level of } \\
\text { anxiety }\end{array}$ & $-0,896$ \\
\hline $\begin{array}{l}\text { Scale 5. Parental love ST - total } \\
\text { anxiety level }\end{array}$ & $\begin{array}{l}\text { 3Т - загальний рівень } \\
\text { тривожності }\end{array}$ & 0,913 \\
\hline $\mathrm{T}-$ alarm & ST - total anxiety level & 0,989 \\
\hline cooperation & $\begin{array}{l}\text { SS cooperation } \\
- \text { the subject of } \\
\text { communication }\end{array}$ & $-0,920$ \\
\hline
\end{tabular}


they are provided for themselves), the situation results in underdevelopment of the child's self-awareness.

The underdevelopment of the child as a subject of play activities correlates with the general communicative tolerance of parents, in particular categoricalness or conservatism in other people's assessments $(r=-0.953)$, inability to hide or smooth out unpleasant feelings when confronted with uncommunicative qualities of partners $(\mathrm{r}=-0.980)$.

Most families of maladaptive children have a high level of anxiety. Anxiety in the family often leads to a symbiotic relationship with a child $(\mathrm{r}=0.889)$. Such parents try to protect the child from difficulties and troubles. When the level of anxiety increases, the indicators of the child's development as a subject of communication decrease $(\mathrm{r}=-0,920)$. Family anxiety promotes awareness of parental feelings $(r=0.889)$, encourages parents to be more attentive to the achievements and interests of the child $(r=0.913)$, stimulates parental love $(r=0.989)$. However, the higher the overall level of anxiety in the family, the lower the parental responsibility $(r=-0.896)$.

The reduction of parental responsibility has a negative impact on the entire system of family upbringing. In particular, parents can indulge the child in everything, bring it (him or her) up in an atmosphere of permissiveness like a «family idol» or, conversely, like a scapegoat. Intolerant parents, in addition to communicative intolerance, also have a reduced level of awareness of such components of parenthood as parental responsibility, parental attitudes, style of family upbringing. They have a reduced level of development of positive parental feelings, a pronounced desire for a symbiotic relationship with the child. Children of intolerant parents have poorly formed subjective personality traits, manifestsociopedagogical neglect and maladaptation.

During the research period corrective work was carried out in the period from January 2019 to March 2020. All in all, 10 classes were held with beginning teachers and 5 classes with parents of primary schoolschildren. Classes were held once a week. The duration of each lesson was 20-30 minutes. Classes were held as a group work. When organizing classes, we relied on the following principles:

1. The principle of activity of group members: during classes participants are constantly involved in various activities - discussion and playing rolegame situations, etc. 
2. The principle of the research position: in the process of working in a group, special situations are created for participants to find the solution to the problem on their own;

3. The principle of objectification of behavior: at the beginning of classes the behavior of group members is translated from impulsive to objectified level and is maintained at this level during all the time;

4. The principle of partnership: work in groups is based on the recognition of the value of another person's personality, his thoughts and interests. All decisions are made taking into account as much as possible the interests of all participants of communication, but not with the aim of achieving one's goal at the expense of the interests of others pupils of primary schools and to find out the efficiency of the developed correctional program.

During research the following results were received. The results of diagnostics of teachers' personality with the help of a 16 - factor Kettel questionnaire (form C) are presented. Comparing the data obtained at the beginning and the end of the experiment we've got the following results:

Table 1.5

\section{Characteristics of the correlation matrix of Kettell indicators of tolerant and intolerant teachers at the beginning and end of the experiment}

\begin{tabular}{|l|c|c|c|c|}
\hline \multirow{2}{*}{$\begin{array}{c}\text { Characteristics } \\
\text { of the correlation matrix }\end{array}$} & \multicolumn{2}{|c|}{ Tolerant teachers } & \multicolumn{2}{c|}{ Intolerant teachers } \\
\cline { 2 - 5 } & PE & KE & PE & KE \\
\hline Coherence & 44 & 43 & 32 & 27 \\
\hline Divergence & 7 & 8 & 19 & 24 \\
\hline General organization of the structure & 51 & 51 & 51 & 51 \\
\hline $\begin{array}{l}\text { The coefficient of the general } \\
\text { organization of the structure is }\end{array}$ & 0,17 & 0 & 0,11 & \\
\hline
\end{tabular}

We can state that the majority of respondents who had low results at the beginning of our work (by all methods), after its completion came to an average level. And those respondents who had average scores reached a high level. A direct correlation was found between the parameters «subject of self-awareness» and cooperation as a type of parental attitude $(r=0.879)$. Because neglected children have low rates of cooperation with their parents and more often they are provided for themselves, they tend to underdeveloped self-awareness. 


\section{Interconnection of parameters of parental tolerance with personality development}

\begin{tabular}{|c|c|c|}
\hline \multicolumn{2}{|c|}{ Correlation relations between the parameters } & \multirow[t]{2}{*}{$\begin{array}{l}\text { Correlation coefficient } \\
(\mathrm{r}) \text { at } \mathrm{n}=5 \text {, } \\
\text { rcrit }=0.878 \text { for } \mathrm{p} \leq 0.05\end{array}$} \\
\hline Cooperation & $\begin{array}{l}\text { Parameters of the child's } \\
\text { personality development }\end{array}$ & \\
\hline symbiosis & $\begin{array}{l}\text { The SS is a subject of } \\
\text { self-knowledge }\end{array}$ & 0,880 \\
\hline $\begin{array}{l}\text { Scale 3. Categoricalness or } \\
\text { conservatism in the assessments } \\
\text { of other people }\end{array}$ & ST - total anxiety level & 0,890 \\
\hline $\begin{array}{l}\text { Scale 4. Inability to hide } \\
\text { or smooth out unpleasant } \\
\text { feelings when confronted with } \\
\text { uncommunicative qualities of } \\
\text { partners }\end{array}$ & $\begin{array}{l}\text { LED is a subject of } \\
\text { gaming activity }\end{array}$ & $-0,805$ \\
\hline $\mathrm{BP}$ - parental feelings & $\begin{array}{l}\text { SID - the subject of } \\
\text { gaming }\end{array}$ & $-0,998$ \\
\hline BV - parental responsibility & ST - total anxiety level & 0,982 \\
\hline $\begin{array}{l}\text { Scale } 3 . \text { Positive feelings } \\
\text { towards the child are due to his } \\
\text { strengths and achievements }\end{array}$ & $\begin{array}{l}\text { ST - general level of } \\
\text { anxiety }\end{array}$ & $-0,903$ \\
\hline $\begin{array}{l}\text { Scale 5. Parental love ST - total } \\
\text { anxiety level }\end{array}$ & ST - total anxiety level & 0,989 \\
\hline $\mathrm{T}-$ alarm & & 0,913 \\
\hline cooperation & $\begin{array}{l}\text { SS cooperation } \\
\text { - the subject of } \\
\text { communication }\end{array}$ & $-0,950$ \\
\hline
\end{tabular}

The molding experiment on implementation of correctional program of tolerant attitude to primary schools children confirmed its effectiveness, which was reflected in the reduction of the number of teachers with a low level of tolerance; increasing the percentage of respondents with an average level of tolerance; growing number of teachers ready for a tolerant education at a high level.

Therefore, we can confirm that primary school teachers who have registered indicators, characteristic of a high level of cognitive, emotional and communicative components of teachers ' tolerant attitude 
towards primary school children (29), 91\%, have mastered basics of tolerant education and the ability to apply it in their professional activity. They showed a tolerant attitude as a stable attitude to tolerant learning and a positive emotional attitude to various manifestations of pupils' alienation, showed the ability to create a positive emotional background during the learning process, the ability to set goals and organize learning activities based on the each person's consciousness in its various manifestations; the ability to create a tolerant educational environment and fill the existing educational environment with tolerant content; ability to implement the pedagogy of partnership; theyare aware of their role in the tolerant upbringing of primary school children and can analyze their activities [8, p. 21].

Primary school teachers who have average level of training $(57.84 \%)$, who generally know the basics of tolerant education, can use some of them in the educational process. Candidates in this category show positive tolerance only at the situational level and are not always emotionally prone to certain manifestations on the part of other pupils. Goal setting and organization of educational activities based on awareness of self-esteem of each person in its various manifestations entails certain complications [10].

Participants of the experiment whose level was low (12,25\%) are more passive and generally weak in learning. They demonstrate a fragmentary knowledge of the basics of tolerant education, tolerance is manifested situation ally, but they are indifferent to the manifestations of others, it is difficult for them to create a positive emotional background of the educational process. These teachers do not know properly interests and values of each person and cannot create a tolerant educational environment on their own, but in the existing educational environment they can provide elements of tolerant content. Their knowledge of partnership pedagogy is just a guide for them, thoughthey still have some of its methods. When they analyze their activities, they have some complications and are poorly aware of their role in the tolerant upbringing of primary school children. The results of dividing would-be primary school teachers at the beginning and the end of the experiment based on tolerance levels in tolerant education are presented in Figure 1.3 and Figure 1.4. 
Analysis of the generalization of the results of the molding experiment

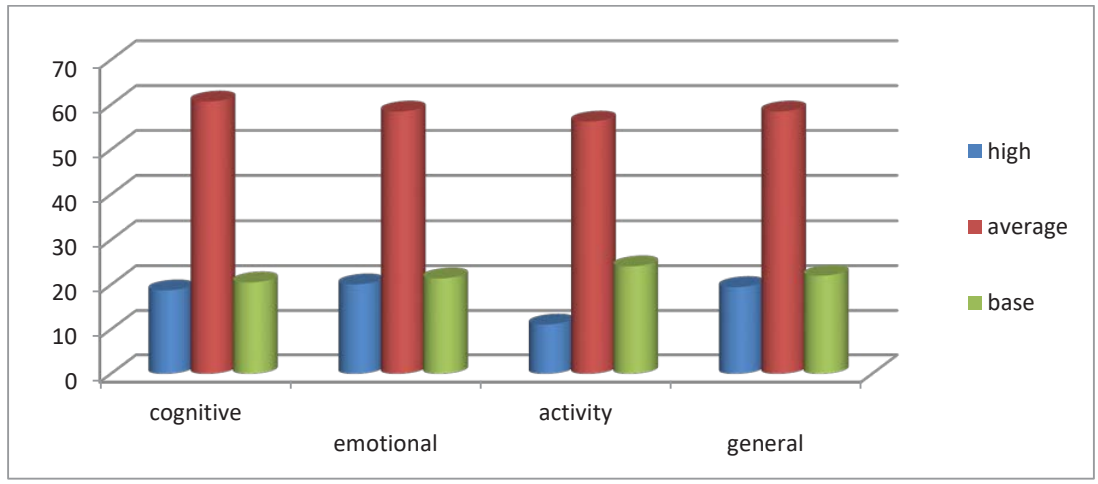

Figure 1.3. Results at the beginning of the experiment

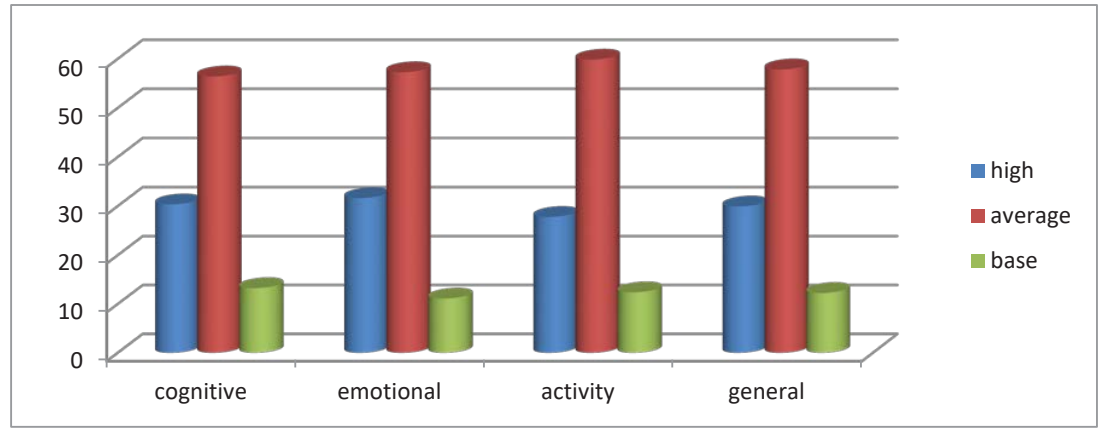

Figure 1.4. Results at the end of the experiment

Educational experiment on the implementation of a correctional program for teachers being trained tolerant education of primary school children has shown its effectiveness, which has led to a more intense reduction in vigilance (from $34.33 \%$ to $12.25 \%)(-22.08 \%)$; training (from $48.72 \%$ to $57.84 \%(+9.12 \%)$ of the EU; increase in the number of teachers ready for tolerant education at a high level (from $16.95 \%$ to $29.91 \%(+12.96 \%)$

The reliability of matches and control differences were determined by calculating the t-test which made it possible to formulate two hypotheses: 
Calculation of the average score of the level of tolerant attitude towards junior schoolchildren

\begin{tabular}{|c|c|c|c|c|c|}
\hline \multicolumn{2}{|c|}{ At the beginning of the experiment } & \multicolumn{3}{|c|}{ At the end of the study } \\
\hline Score & $\begin{array}{c}\text { Total } \\
\text { number } \\
\text { points }\end{array}$ & $\begin{array}{c}\text { Average } \\
\text { value }\end{array}$ & Score & $\begin{array}{c}\text { Total } \\
\text { number } \\
\text { points }\end{array}$ & $\begin{array}{c}\text { Average } \\
\text { value }\end{array}$ \\
\hline 5 & 220 & & 5 & 350 & \\
\hline 4 & 524 & & 4 & 540 & \\
\hline 3 & 147 & & 3 & 87 & \\
\hline$\sum$ & 891 & 3,977 & $\sum$ & 977 & 4,175 \\
\hline
\end{tabular}

Hypothesis H0: differences in the level of tolerant attitude of teachers to children of elementary schools at the beginning and end of the experiment are not significant enough. Hypothesis $\mathrm{H} 1$ : differences in the level of tolerant attitude of teachers to children of elementary schools at the beginning and end of the study are quite significant.

To calculate the t-test the variance was determined. The calculation of the variation of teachers' level of training for tolerant upbringing of primary school children is presented in Table 1.8.

Table 1.8

Calculation of the variance of the level of training teachers for tolerant education of primary school children

\begin{tabular}{|c|c|c|c|c|c|c|c|}
\hline Groups & $\begin{array}{l}\text { Evalua- } \\
\text { tion }\end{array}$ & $\begin{array}{c}\text { Number } \\
\text { of } \\
\text { marks }\end{array}$ & $\begin{array}{c}\text { Average } \\
\text { score }\end{array}$ & $\begin{array}{c}\text { Devia- } \\
\text { tion }\end{array}$ & $\begin{array}{c}\text { Deviation } \\
\text { square }\end{array}$ & & $\mathbf{S}$ \\
\hline \multirow{3}{*}{ EG } & 3 & 29 & \multirow{3}{*}{4,175} & $-1,175$ & 1,380625 & 4,141875 & \multirow{3}{*}{0,0329} \\
\hline & 4 & 135 & & $-0,175$ & 0,030625 & 0,1225 & \\
\hline & 5 & 70 & & 0,825 & 0,680625 & 3,403125 & \\
\hline \multirow{3}{*}{$\mathrm{KG}$} & 3 & 49 & \multirow{3}{*}{3,977} & $-0,977$ & 0,954529 & 2,863587 & \multirow{3}{*}{0,0363} \\
\hline & 4 & 131 & & 0,023 & 0,000529 & 0,002116 & \\
\hline & 5 & 44 & & 1,023 & 1,046529 & 5,232645 & \\
\hline
\end{tabular}

The variance was got, the value of the t-test were calculated: 
The date in the table for the Student's t-test is less than the calculated value. This means that the null hypothesis is rejected and hypothesis H1 is accepted if the difference in the level of preparation of would-be teachers for tolerant education of primary school children in the experimental and control groups with a probability of $95 \%$.

The positive dynamics in training teachers for tolerant education of primary school children, in particular its qualitative and quantitative indicators, testifies to efficiency of the program suggested and its possible application for training teaches of primary schools tolerant attitude to schoolchildren.

\section{Conclusion}

The implementation of teachers and parents program of tolerant education of primary school children passed through three stages. The motivational stage (component of emotional value) aims at giving teachers and parents some knowledge on basics of tolerant education, pedagogy of partnership. The stage of educational activity (part of cognitive and communicative activity) provides teachers and parents with the knowledge on mechanism and forms of implementing tolerant education in upbringing process as well as develops skills of how to prevent conflicts, regulate emotions and get use of methods, techniques and devices for tolerant education («Pedagogy», «Fundamentals of pedagogical skills»). Reflexive stage (activity and communication ) is aimed at training teachers and parents to analyze their own activity as to tolerant education of primary schoolchildren; developing a vision of a multicultural world, the values of tolerant education, empathy, the implementation of pedagogical partnership.

Training experiment on the implementation of the program of training tolerant attitude of teachers and parents to primary school children confirmed its efficiency, which was reflected in a decrease in the number of teachers who had a low level of tolerance (from $34.33 \%$ to $12.25 \%$ ) $(-9.52 \%))$; increase in the percentage of respondents with an average level of tolerance (from $48.72 \%$ to $57.84 \%(+9.12 \%)$ ); increase in the number of teachers ready for tolerant education at a high level (from $16.95 \%$ to $29.91 \%(+12.96 \%)$.

Thus, the reliability and objectivity of the results of the experimental study were confirmed by methods of mathematical statistics (calculation 
Pearson's nonparametric criterion) and by checking the heterogeneity at the beginning and the end of the experiment (Student's t-test), which indicates the efficiency of the program developed and the possibility of its further application in the process of training primary school teachers tolerant attitude to children.

\section{References:}

1. Gaidamashchuk M. (2020). Tolerance as the basis for the formation of civilized relations. Primary School Teacher, no. 12, pp. 53-55.

2. Geertz K. (2004). Interpretation of cultures. ROSSPEN, 555 p.

3. Iskra L. (2014). Practical implementation of ideas of education in the spirit of peace in the educational process. Young Scientist, no. 12, pp. 297-300.

4. Karpov L. (2003). Journal search results - Cite This For Me. Metal Science and Heat Treatment, no. 45(1/2), pp. 8-9.

5. Kononko O. (2018). Healthy Education In Early Onthenhenesis: Theoretical And Technological Aspects. Scientific Bulletin of KRHPA, no. 10, pp. 152-161. doi:10.37835/2410-2075-2018-10-15

6. The concept of development of pedagogical education. URL: www.pro-zatverdzhennya-koncepciyi-rozvitku-pedagogichnoyi-osviti

7. «SS» (2017). Correctional and developmental program for the formation of stress resistance in preschoolers and schoolchildren (published by GLYF Media, Volume 208s). NaUKMA.

8. Korzhova O.V. (1997). Educating adolescents for the ideas of peace in extracurricular activities. Author. dis. for science. Ph.D. degree ped. science: special, 21 p.

9. Kremen' V.G. (2011). «Filosofiya antropocentrizma v obrazovatel'nom prostranstve». T-vo «Znannya» Ukraini, $520 \mathrm{p}$.

10.Kupriyanov B.V., Nekrasov N.A. (2010). Sovremennye podhody k opredeleniyu sushchnosti kategorii «pedagogicheskie usloviya». Vestnik Kostromskogo gos. un-ta, pp. 101-104.

11. Courland Z.N. (1995). Professional stability of the teacher. Odessa, $150 \mathrm{p}$.

12. Lyulka G.A. (2019). Interactive technologies for the formation of a tolerant attitude of primary school teachers to students. Young scientist, no. 11.

13. Marinovska O.Ya. (2019). Pedagogical innovation \& Innovation Management. Ivano-Frankivsk: teaching method. Manual, 504 p. 